\title{
How to choose a fruitful research project: advice from graduate students
}

\author{
Lee-Anne Huber ${ }^{*}$, Alexandra Guselle ${ }^{\S}$ \\ * Department of Animal \& Poultry Science, ${ }^{\S}$ School of English and Theatre Studies \\ University of Guelph, Guelph, Ontario, Canada
}

\begin{abstract}
Selecting a research topic is an integral part of graduate studies. According to Skip Brass, Associate Dean and Director of the MD-PhD program at the University of Pennsylvania, you need to "pick a problem that interests you. You will be living with it for a long time. Make sure it is something you will want to wrestle with even when the going gets rough. It has to make you want to get up early, work late, come in on the weekend, and think about it in the shower." This paper aims to make the process of choosing and evaluating a research topic a little easier through providing some helpful steps in formulating a successful project.
\end{abstract}

$\mathrm{G}^{\mathrm{s}}$ raduate studies are an opportunity to investigate issues within a discipline that you find personally and professionally intriguing. Unlike undergraduate degrees which usually have a set coursework structure, graduate studies are an opportunity to explore new methods of uncovering and conceptualizing knowledge. For the first time in your academic career, you are able to narrow your field of interest and explore topics that are relevant to your career goals. The independent learning structure in graduate studies helps build your confidence in preparation for future jobs in the workplace. The paper will guide you through four steps in choosing a research topic, including: discovering your passion, choosing the right institution and advisor, surveying the literature, and mapping out where graduate studies will take you. This paper aims to help you channel your academic interests into a research focus that will make your project both enjoyable and original; laying the groundwork for future study.

\section{Discovering Your Passion}

Designing and executing a research project is no easy feat. The research you undertake will consume countless hours of time and effort out of your day for months or even years. For this reason, it is critical to consider areas of study that you are both passionate and curious about. No matter how great your advisor or institution is, if you're not interested in what you're researching then your project will not turn out the way you want it to. When you choose to investigate a problem that intrigues you it will always seem less like work. While you should expect that your research, and morale, will hit rough spots no matter how passionate you are about the topic, looking at issues you are fascinated by will ultimately be more rewarding. This way you are more likely to commit the time required to complete your graduate work without getting overly discouraged.

\section{DO THE RESEARCH}

Before committing to a research topic, it is important to consider how the institution, department, faculty, and funding will all play a role in your work. Choosing the school to complete your graduate work in is usually based on preference, convenience and comfort. You may choose however, to use graduate studies as an opportunity to travel to other countries and experience different cultures. Keep in mind that people who complete graduate work overseas or in neighboring countries often reside in those areas afterward. This is because sponsoring companies and employers become familiar with your work quality and attributes for hire. If you are interested in working abroad, consider attending an institution in the country in which you would like to work.

If you are pursuing a graduate research project in the sciences, the department and laboratory you choose are very important. Conduct an investigation of the facilities to ensure that the department produces plenty of meaningful and lucrative research. Also, make sure the laboratory is outfitted with up-to-date equipment that will allow you to complete experiments efficiently and accurately.

A large aspect of which institution you will attend should be based on the faculty member you hope to have as an advisor. You also need to consider carefully the advisor you are choosing. Do research of your own before approaching him/her. Does he/she produce ample amounts of consequential research each year? Is this research in areas that interest you? It is the faculty's job to be willing to talk to you and answer your questions, so do not hesitate to visit 
multiple faculty members to "shop around" and see who would be the best fit for you. It is important to ensure that the advisor you choose will be available throughout your entire researching process, from initial consultation to the final edits. Make sure the advisor you choose is not planning any immediate sabbaticals that could disrupt your research.

Talk to current graduate students, laboratory technicians and teaching assistants to get a feel for your advisor and, in the case of the sciences, the laboratory that he/she runs. You will start as your advisor's apprentice but with hard work and perseverance you will finish as a colleague. This can be a fruitful relationship as long as the fit is right.

The bottom line usually comes down to funding. If there is not money available for you at the institution you want to attend, then you will have to apply for your own scholarships. Depending on the department, funding may come in the form of teaching and research assistant positions, stipends, bursaries or scholarships. Some departments only take graduate students if they are able to fund them, while others require you to provide your own sources of funding. Ultimately, you may have to face the fact that money might not be available in the department you want to join, in which case you will have to look for graduate positions at other institutions.

\section{EXAMINE THE LITERATURE}

Whether you are interested in doing a research paper or a thesis, it is important that you are able to demonstrate familiarity with existing work in your field. Before narrowing in on a research topic, do a broad survey of the existing scholarship in your chosen field. Categorizing the literature into different perspectives will allow you to explore what critical and theoretical positions have been taken in the past. This process will also inform on ways that you can approach the research that will lay the groundwork for your project. Not only will this activity give you a greater understanding of ongoing dialogue in the literature about a topic, it will allow you to evaluate unquestioned assumptions. Uncovering holes or gaps in existing research is an integral part of designing your own research question. As you'll quickly learn in graduate school, the best projects are not those that attempt to take on huge unchartered territory. The research projects that generally have the greatest success are those that tackle a manageable gap in existing thought, and in doing so, lay the foundation for further research. Once you have decided on a general area of research, work with your advisor or professors to design a reading list that will familiarize you with the complexities and opportunities a literature review has to offer.

\section{Where Will It TAKe You?}

Career advancement is often the main motivation for graduate studies and ideally at the end of your degree you will be further ahead on your career path. Many Master's programs are designed to prepare students for doctoral degrees. If becoming a professor is your ultimate career goal, then use your graduate research as an opportunity, not only to develop your critical voice, but also to learn the ins-andouts of academic networking, conferencing, and teaching. Whereas the majority of undergraduate degrees cover a broad range of subjects within a given discipline, the research topic you choose will provide a much narrower and more focused scope of what you're interested in. Whether this is swine nutrition or nineteenth-century literature, being able to formulate a research questions based on your specific interests will give you the opportunity to develop and evaluate your academic and professional interests further than ever before.

While graduate school expands your research, writing, and teaching skills, it is necessary to consider job marketability. Whether this means getting a new job or entering a new field, you should examine the amount of career development skills your research program will provide you with. Designing and executing a research project takes a large amount of time and effort. Before deciding on your research topic, it is important to evaluate your strengths and weaknesses and decide where you want your research to take you. Being able to visualize where you want to be at the end of your project will help make all the stress and hard work worthwhile. If your dream isn't to become a professor, consider what skills you will develop that will make you more marketable in your future career. Having a graduate degree will give you a competitive edge in many fields so it is a good idea to use your research project as a way of demonstrating to future employers how you will be successful outside of the university institution. At the end of the day, graduate school will help you to develop skills that will be useful in any career you choose. Using your research as a way of projecting your strengths to employers will only help you achieve your career goals faster.

\section{CONCLUSION}

If you are unsure about what you want to research, don't be scared. Faculty and academic counselors are there to help you narrow your research topic. Many people go through several thesis ideas before they find the right fit, so don't be discouraged. A good research project is one that both fulfills your passion and advances your skills as a researcher. Use your research project as an opportunity to contribute new knowledge to the research community and direct further discovery. 